\title{
A cross sectional study of employees with potential occupational exposure to ethylene oxide
}

\author{
M F CURRIER,' G L CARLO, ${ }^{2}$ P L POSTON,' AND W E LEDFORD ${ }^{3}$ \\ From the Medical' and Industrial Hygiene ${ }^{3}$ Departments, Louisiana Division, Dow Chemical USA, \\ Plaquemine, Louisiana 70764, and US Area Epidemiology, ${ }^{2}$ Health and Environmental Sciences, Dow \\ Chemical USA, Midland, Michigan 48640, USA
}

\begin{abstract}
A cross sectional study was conducted on 84 employees potentially exposed to ethylene oxide (EO) to determine whether they had a higher prevalence of abnormalities of the haematopoietic, hepatic, or renal systems than a control group individually matched on age, hire date, race, smoking habits, alcohol history, and date of examination. Potential exposures were estimated to be generally below the current threshold limit value of $10 \mathrm{ppm}$, with most below 1 ppm. Results of the haematological and biochemical studies were similar in the two groups. A statistically significant $(p=0.035)$ increase in the prevalence of proteinuria was noted among the EO group which warrants further investigation.
\end{abstract}

Ethylene oxide (EO) is an important industrial chemical used in the manufacture of such products as ethylene glycol, polyesters, nonionic surface active agents, heavy duty home laundry detergents, and glycol ethers.' It is also used as a pesticide fumigant and a cold sterilant for medical equipment. At room temperature and normal atmospheric pressure it is a colourless gas; at higher pressures it may be a volatile liquid. In the United States, where $43 \%$ of the world production capacity is held, production of EO has increased from 1.3 billion pounds in 1960 to 5.3 billion pounds in 1979 .

Acute intoxication with EO at high concentrations has been recognised as a cause of eye, respiratory tract, and skin irritation, and of central nervous system depression. ${ }^{2}$ Suspected delayed effects include headache, nausea, vomiting, incoordination, and electrocardiography abnormalities. Concentrations responsible for acute effects have been estimated at above $2000 \mathrm{ppm}$ for very short single exposures and above $200 \mathrm{ppm}$ for continuous eight hour exposures. ${ }^{3}$ The American Conference of Governmental Industrial Hygienists lists in its 1981 booklet an eight hour time weighted average (TWA) concentration of $10 \mathrm{ppm}$ for the EO threshold limit value (TLV) with a proposed intended change to $5 \mathrm{ppm}$. The current OSHA permissible exposure limit (PEL) is 50 ppm TWA.

Received 23 May 1983

Accepted 11 July 1983
The first epidemiological inquiry into the possibility of adverse chronic effects resulting from exposure to EO was reported in $1964 .^{4}$ This cross sectional study involved 37 EO operators engaged in manufacturing operations, and age matched control operators working with chemicals other than EO. The highest air concentrations of EO recorded was $127 \mathrm{ppm}$; however, the average concentrations were less than $10 \mathrm{ppm}$ for the working day. In their study the EO group reported fewer symptoms and less absenteeism than the controls; the frequency of "abnormal" laboratory findings in the study and control groups was similar.

In more recent years, however, epidemiological studies have suggested positive associations between exposure to EO and human illness. For example, a cross sectional study of employees using EO in cold sterilisation showed varying frequencies of symptoms, such as sore throat, in 12 exposed employees versus no symptoms of any type in a control group. ${ }^{5}$ Cytogenetic studies by the same investigators reportedly showed more frequent sister chromatid exchanges (SCEs) among the 12 employees than among the 11 controls (average SCEs 8.65 versus 6.37). Another investigation reported peripheral neuropathy with decreased nerve conduction velocity in four men after overexposure to EO. ${ }^{6}$

Concern has been expressed also about the possible carcinogenicity of EO. Results of an industry sponsored inhalation study showed an increased, dose related incidence of mononuclear cell 92 
leukaemia in male and female Fischer 344 rats. ${ }^{7}$ Effects were noted at exposure concentrations of 100,33 , and $10 \mathrm{ppm}$. Because of the chemical's alkylating agent properties, ${ }^{8}$ and because it is mutagenic in several test systems including Neurospora, ${ }^{9}$ plants, ${ }^{10}$ and the Salmonella typhimurium stain TA 1535 bacterial assay, ${ }^{11}$ carcinogenicity is biologically plausible.

Recently, there have been two reports from Sweden concerning human malignancies allegedly associated with exposure to EO. The first was of a case each of acute myelogenous leukaemia, chronic myelogenous leukaemia, and Waldenström's macroglobulinaemia, diagnosed between 1972 and 1977 in employees of a small factory that used EO for sterilisation..$^{12}$ In a subsequent retrospective mortality study of employees in an EO production plant the same author reported more deaths from leukaemia than would have been expected ( 3 observed compared with less than 0.5 expected) using Swedish national death rates as a standard. ${ }^{13}$ Two of the deaths from leukaemia were caused by chronic lymphatic leukaemia and one by acute myeloid leukaemia. The significance of these epidemiological findings is limited, however, by the small number of observed deaths and the uncertainty of the degree of exposure. A more recent cohort mortality study by Morgan et al showed no deaths from leukaemia in EO workers. ${ }^{14}$

Since the results of these studies of exposure to EO were conflicting, we have carried out a further study to assess the relation between exposure to EO and possible adverse effects on health on a cohort of employees in a large US chemical manufacturing complex.

The first objective was to identify the group of workers engaged in processes with potential exposure to EO and the group who have never worked in such processes. These determinations, based on individual work histories, process descriptions, and process specific industrial hygiene information were to be used to classify individuals as potentially exposed or unexposed. ${ }^{*}$ The a priori definition of these groups was seen as important in expediting any future EO studies. The second objective was to determine whether potentially exposed workers had a higher prevalence of abnormalities of the haematopoietic, hepatic, and renal systems, as measured by data collected through periodic health

\footnotetext{
"Throughout this report, the terms "potentially exposed" and "unexposed" are used to describe this independent variable. Process specific industrial hygiene information has been used in assessing exposure but exposure measurements were not carried out on all the individuals included in the study. Therefore, as groups, their technical status, from an epidemiological perspective, is potentially exposed or unexposed.
}

examinations, than an appropriately matched group of unexposed workers.

\section{Materials and methods}

\section{COHORT IDENTIFICATION}

Process description and exposure information

Within the chemical manufacturing complex there are two groups of employees who may be exposed to EO. In the first group were those individuals who produce EO and ethylene glycol. In the second group, considered mainly as users of EO, were those employees who produce glycol ethers and ethanolamines. Personnel sampling for exposure to EO has been carried out at various times on both groups of workers by collecting breathing air zone samples on to activated charcoal. Samples are desorbed with carbon disulphide and analysed by flame ionisation gas chromatography. All measured eight hour TWA exposures to EO for those employees producing EO and ethylene glycol have been well below the current TLV of $10 \mathrm{ppm}$. The loading operating technicians have had the highest exposures, with a range of yearly average TWA exposures from $<1.0 \mathrm{ppm}$ in 1977 to $1.7 \mathrm{ppm}$ in 1980 . Among this group, the range of individual measurements has been $<0.1 \mathrm{ppm}$ to $5.7 \mathrm{ppm}$. All other jobs have had yearly average TWA exposures below $1.0 \mathrm{ppm}$. Grab samples taken since 1973 to determine peak exposure levels have indicated short time period excursions for the loading job as high as $235 \mathrm{ppm}$ (in 1976), whereas all other jobs had peak exposures below $100 \mathrm{ppm}$, with most being below $20 \mathrm{ppm}$. Since the loading job requires wearing a supplied air respirator, the exposure measurements for this job represent potential exposures only. Other chemicals to which EO and ethylene glycol production employees might be exposed include ethylene dichloride (EDC), Dowtherm* A (biphenyl and biphenyl oxide), and ethylene glycol. Exposure levels for all of these have been well below their respective TLVs.

The highest recorded EO exposure among personnel producing glycol ethers and ethanolamines was $0.1 \mathrm{ppm}$, during the bleeding down of some EO containing equipment in 1980 . Other chemicals to which these employees might be exposed include propylene oxide, methanol, butanol, ammonia, the mono-, di-, and tri-ethanolamines, and glycol ethers. For the most part, eight hour TWA exposures to these chemicals are generally below $1.0 \mathrm{ppm}$.

*Trademark of the Dow Chemical Company. 


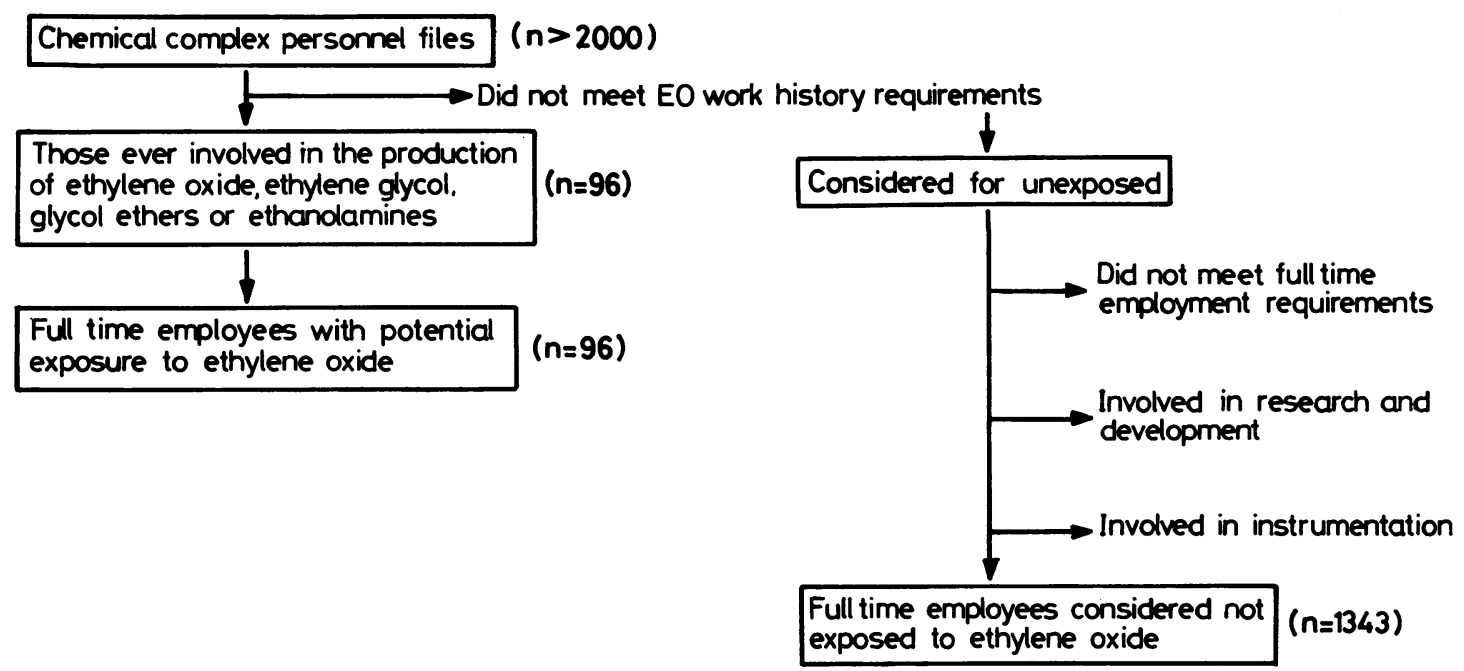

Identification of potentially exposed and unexposed populations.

Definition of the potentially exposed and unexposed populations

The procedure by which the potentially exposed and unexposed populations were identified is outlined in the figure. In the potentially exposed group were full time employees who had ever produced EO, ethylene glycol, glycol ethers, or ethanolamines as identified through personnel lists. The group of individuals who did not meet the work history requirement was considered as candidates for the unexposed group. Those who were not full time employees and those who worked in either research and development or instrumentation were eliminated from this group because their overall exposures were probably ill defined. The total number of employees considered as unexposed was 1343.

\section{CROSS SECTIONAL MEDICAL SURVEILLANCE STUDY}

The major analytical portion of this research entailed assessing of whether the prevalence of certain abnormalities of the haematopoietic, hepatic, and renal systems differed in the workers potentially exposed and in matched unexposed workers.

\section{POTENTIALLY EXPOSED AND UNEXPOSED GROUPS}

All employees who had been working for at least six months in the processes with potential exposure to EO before the time of their 1980 health examination were extracted from the overall list of potentially exposed. Employees with previous service in these areas were not included in the study group, but neither were they eligible to become controls. Women were not included because there were so few, and it was also necessary to exclude men for whom complete 1980 health examination data were not available. Thus from the 96 individuals in the original pool of potentially exposed, six women and six men with insufficient medical surveillance data were eliminated. The 84 employees remaining represented $93.3 \%$ of the total group of those potentially exposed.

Altogether 127 women, 75 individuals with less than six months employment within the chemical complex, and 87 individuals judged to have potential exposure to benzene (benzene is suspected of having haematopoietic effects and thus might be considered a competing exposure) were eliminated from the unexposed list. Another 93 individuals were eliminated because they did not participate in the 1980 medical surveillance programme. The remaining 939 individuals eligible for control matching represented $91.1 \%$ of the original unexposed pool.

A single unexposed control was then matched with each member of the potentially exposed group. For each employee in the potentially exposed group, a search of the entire group of unexposed was undertaken to find candidates for control matching. If a control candidate was previously selected as a control match he was excluded from the process for any subsequent matching. The matching criteria, in order of importance, were as follows: age (within five year intervals), hire date ( \pm 5 years), race, smoking history (non-smoker, current cigarette 
Table 1 Laboratory test outcome variables, reference ranges and suspected direction of value change if an effect is present

\begin{tabular}{|c|c|c|c|}
\hline Group & Test & Reference range & Suspected direction of change if effect present \\
\hline Haematology* & $\begin{array}{l}\text { Hb } \\
\text { Hct } \\
\text { RBC } \\
\text { WBC } \\
\text { Per cent lymphocytes }\end{array}$ & $\begin{array}{l}14-18 \mathrm{~g} / \mathrm{dl} \\
40-54 \% \\
4 \cdot 6-6 \cdot 2 \text { million } / \mathrm{mm}^{3} \\
4 \cdot 5-11 \cdot 0 \text { thousand } / \mathrm{mm}^{3} \\
25-33 \%\end{array}$ & $\begin{array}{l}\text { Low } \\
\text { Low } \\
\text { Low } \\
\text { Low or high } \\
\text { Low or high }\end{array}$ \\
\hline & $\begin{array}{l}\text { BUN } \\
\text { Serum creatinine } \\
\text { Urine protein } \\
\text { (1+ or greater) } \\
\text { RBC } \\
\text { WBC }\end{array}$ & $\begin{array}{l}8-26 \mathrm{mg} / \mathrm{dl} \\
0.9-1.4 \mathrm{mg} / \mathrm{dl} \\
\text { Negative } \\
2 \\
0-3\end{array}$ & $\begin{array}{l}\text { High } \\
\text { High } \\
\text { High } \\
\text { High } \\
\text { High }\end{array}$ \\
\hline Sive & $\begin{array}{l}\text { Total bilirubin } \\
\text { Alkaline phosphatase } \\
\text { LDH } \\
\text { SGPT } \\
\text { SGOT } \\
\text { GGTP }\end{array}$ & $\begin{array}{l}<1.6 \mathrm{mg} / \mathrm{dl} \\
35-148 \text { units } \\
63-155 \mathrm{IU} / \mathrm{l} \\
12-53 \text { units } \\
15-55 \text { units } \\
<38 \text { U/l }\end{array}$ & $\begin{array}{l}\text { High } \\
\text { High } \\
\text { High } \\
\text { High } \\
\text { High } \\
\text { High }\end{array}$ \\
\hline
\end{tabular}

"Reference range based on Conn. ${ }^{17}$

†Reference range according to Bio-Science Laboratory, Van Nuys, California.

smoker, ex-smokers, and cigar or pipe smokers combined), and alcohol intake (light, moderate, heavy). As a final matching step, the date of the 1980 health surveillance examination was used to minimise the effects of common seasonal occurrences such as influenza, common colds, and laboratory variations that might affect the variables to be studied. This final step was effective in narrowing the number of possible matches for each exposed individual; in no case was there more than one match for an individual after this step. In two cases appropriate matches could not be found. In one instance the date of hire criterion was relaxed from \pm 5 to \pm 6 years for the control, and in another instance the age group criterion was relaxed to match a 19 year old in the 15-19 year age group with a 20 year old in the 20-24 year age group.

\section{Analytical variables}

The analytical outcome variables were extracted from records of results of the 1980 medical surveillance examinations. Table 1 lists the laboratory test variables, their reference ranges, and the suspected directions of the change in value if an effect is present. These tests were considered those most likely to be influenced if EO was, in fact, causing health problems based on a review of published reports.

The exposure variable, or independent variable, was current involvement in the production of EO, ethylene glycol, glycol ethers, or ethanolamines as described above.

The matching criteria described above made it possible to control for the potential confounding variables of age, hire date, race, smoking, and alcohol consumption history, and date of medical surveillance examination.

\section{Statistical analysis}

Since using matched controls made the overall study population appear as "predose" (unexposed) and "postdose" (potentially exposed) populations, and because a normal distribution could not necessarily be assumed, the non-parametric Wilcoxon signed rank test ${ }^{15}$ was used as the analytical statistic for the

Table 2 Results of haematological analyses, individuals potentially exposed to ethylene oxide versus individuals unexposed

\begin{tabular}{|c|c|c|c|c|c|c|}
\hline \multirow[t]{2}{*}{ Outcome variable } & \multicolumn{2}{|c|}{ Wilcoxon's signed rank } & \multicolumn{2}{|c|}{ Exact probability } & \multicolumn{2}{|c|}{ Maxwell-Stuart extension test } \\
\hline & $T \dagger$ & $p$ & $D E A / T D \ddagger$ & $p$ & $x^{2}$ & $p$ \\
\hline $\begin{array}{l}\text { Hb } \\
\text { Hct } \\
\text { RBC } \\
\text { WBC* } \\
\% \text { Lymphocytes* }\end{array}$ & $\begin{array}{r}1.02 \\
1.18 \\
-0.56 \\
-0.69 \\
1.06\end{array}$ & $\begin{array}{rl}> & 0.5 \\
>0.5 & 0.30 \\
& 0.5 \\
& 0.4\end{array}$ & $\begin{array}{l}3 / 7 \\
2 / 3 \\
5 / 9 \\
-\end{array}$ & $\begin{array}{l}>0.5 \\
0.5 \\
0.5 \\
-\quad \\
-\end{array}$ & $\begin{array}{l}\bar{Z} \\
\overline{1 \cdot 14} \\
2 \cdot 06\end{array}$ & $\begin{array}{l}\overline{-} \\
\overline{>} \\
0.5 \\
0.4\end{array}$ \\
\hline
\end{tabular}

*Two tailed test.

$\dagger$ Large sample approximation to normal distribution.

$\ddagger$ Ratio of the number of discordant pairs where potentially exposed was classified as abnormal to the total number of discordant pairs. 
Table 3 Results of renal function analyses, individuals potentially exposed to ethylene oxide versus individuals unexposed

\begin{tabular}{|c|c|c|c|c|}
\hline \multirow[t]{3}{*}{ Outcome variable } & \multicolumn{4}{|c|}{ Test statistic } \\
\hline & \multicolumn{2}{|c|}{ Wilcoxon's signed rank } & \multicolumn{2}{|c|}{ Exact probability } \\
\hline & $T^{*}$ & $p$ & $D E A / T D \dagger$ & $p$ \\
\hline $\begin{array}{l}\text { BUN } \\
\text { Serum creatinine } \\
\text { Urine protein } \\
\text { RBC } \\
\text { WBC }\end{array}$ & $\begin{array}{l}-2 \cdot 02 \\
-0 \cdot 40 \\
- \\
-\end{array}$ & $\begin{array}{l}>0.5 \\
>0.5 \\
= \\
=\end{array}$ & $\begin{array}{l}0 / 0 \\
0 / 0 \\
7 / 8 \\
4 / 8 \\
8 / 10\end{array}$ & $\begin{array}{l}- \\
- \\
0.04 \\
>0.5 \\
0.06\end{array}$ \\
\hline
\end{tabular}

*Large sample approximation.

†Ratio of the number of discordant pairs where potentially exposed was classified as abnormal to the total number of discordant pairs.

continuous data. The value for the unexposed subject was subtracted from the value for the potentially exposed subject and both the positive rank sum statistic $(T+)$ and the large sample approximation $\left(T^{*}\right)$ to the normal distribution were calculated. A $p$ value was then calculated based on $T^{*}$ to test the hypothesis of a zero median difference between the two populations. The continuous variables analysed in this manner were: $\mathrm{Hb}, \mathrm{Hct}, \mathrm{RBC}$, WBC, per cent lymphocytes, total bilirubin, alkaline phosphatase, LDH, SGPT, SGOT, GGTP, BUN, and serum creatinine. In addition, because of the clinical implications of values outside a given reference range, these data were also analysed as dichotomous or multichotomous variables. For those variables where the implications were important for values either above (blood chemistries and kidney functions) or below ( $\mathrm{Hb}, \mathrm{Hct}$, and $\mathrm{RBC})$ the reference range, each value was categorised as being normal (within the reference range) or abnormal. A $p$ value was then calculated, based on the number of discordant pairs ("potentially exposed" versus "unexposed") which indicated more abnormals among the

Table 4 Results of blood chemistry analyses, individuals potentially exposed to ethylene oxide versus individuals unexposed

\begin{tabular}{llllll}
\hline Outcome variable & \multicolumn{2}{l}{ Test statistic } \\
\cline { 2 - 3 } & \multicolumn{2}{l}{ Wilcoxon's signed rank } & & \multicolumn{2}{l}{ Exact probability } \\
\cline { 2 - 3 } & \multicolumn{1}{l}{$T^{*}$} & $p$ & & \multicolumn{2}{l}{ DEA/TD ${ }^{*} p$} \\
\hline Total bilirubin & -0.32 & $>0.5$ & & $2 / 2$ & 0.3 \\
Alkaline phosphatase & 0.90 & 0.2 & & $0 / 1$ & - \\
LDH & -0.45 & $>0.5$ & & $0 / 1$ & - \\
SGPT & 0.52 & 0.3 & & $8 / 14$ & 0.4 \\
SGOT & -0.82 & $>0.5$ & & $3 / 9$ & $>0.5$ \\
GGTP & 0.42 & 0.3 & $5 / 11$ & $>0.5$ \\
\hline
\end{tabular}

*Large sample approximation to normal distribution.

tRatio of the number of discordant pairs where potentially exposed was classified as abnormal to the total number of discordant pairs. potentially exposed, to test the hypotheses that the values were the same in both groups (one tailed exact probability test). ${ }^{15}$ Urine protein, urine WBC, and urine RBC, were also analysed in this manner. Because the implications of values both below and above the reference range for WBC and percent lymphocytes were thought to be important, the Maxwell-Stuart extension of McNemar's test ${ }^{16}$ was used to produce a chi square statistic from which a $p$ value could be derived pertinent to a multichotomous stratification.

\section{Results}

The process of matching the selected potentially exposed and unexposed individuals was efficient; there were no striking differences between the potentially exposed and unexposed groups chosen for analysis, for either the matched variables or selected unmatched variables.

Tables 2, 3, and 4 show the results of the haematological, renal function, and blood chemistry analyses. For interpretive purposes, it should be noted that the higher values for the large sample approximation in the Wilcoxon test $(T)$ indicate that the median value of the potentially exposed group was larger than that in the unexposed. For $\mathrm{Hb}$, Hct, and RBC, the critical test area was at the lower end of the probability curve; therefore, the lower values were of interest. For WBC and per cent lymphocytes, both low and high values were of interest; therefore, two tailed significance tests were applied. For all other variables where the Wilcoxon test was used, a one tailed test considering the higher values as critical was applied. Also, the Wilcoxon's test applied to the continuous data was interpreted as indicative of physiologically significant effects, whereas the exact probability and the MaxwellStuart tests, applied to the "normal/abnormal" categorical data, were interpreted clinically.

None of the differences in haematology between the potentially exposed and unexposed groups approaches statistical significance (table 2). Similarly, the results of the blood chemistry analyses (table 4) show no statistically significant differences between the potentially exposed and unexposed, from either a physiological or a clinical perspective. In table 3, however, it can be seen that a statistically significant excess of individuals within the potentially exposed group had urine protein concentrations above the reference range. Of eight instances where the values for a potentially exposed individual and his matched control were discordant, seven had the abnormal value reported for the potentially exposed individual. The excess of individuals within the potentially exposed group with urine WBC 
above the reference range approached statistical significance.

\section{Discussion}

Cross sectional or prevalence studies are traditionally used to generate hypotheses. As disease incidence is not the outcome measured (since it is not possible to determine whether or not exposure preceded effect), the cross sectional study is generally not appropriate for definitively investigating cause and effect. In this investigation the methodological rigour was enhanced by the incorporation of the one for one matching of potentially exposed with unexposed individuals. Although there was a high participation rate of both those potentially exposed and unexposed in the medical surveillance examination, this type of study design could not take account of the ever exposed pool. Thus an unidentifiable selection bias may have been operating. In addition, with the inclusion of the date of medical surveillance examination as the last matching step, another potential bias was encountered. Because entire plants within the chemical complex were generally scheduled for the examinations each month, the matched control group could have potentially included a disproportionately large number of individuals from a particular plant or plants. If that were the case the comparison studied might be of potential exposure to ethylene oxide and exposure to another chemical, potentially producing an under or over estimation of the prevalence ratios.

To examine this possibility, the distribution of plant specific job titles for the entire chemical complex was determined and compared with the similar distribution among the matched controls. The only discrepancy between the distributions for the two groups was a disproportionally large number of workers from a cellulose production area among the controls $(17.8 \% v 6.6 \%$ of the totals). The chemicals used in the cellulose production area were not considered to be of the type that would affect the health outcomes under study here. Thus this slight discrepancy was judged to be unimportant in terms of affecting the results of the investigation.

Findings of note from this inquiry were the statistically significant excess in the number of potentially exposed with urine protein values above the reference range, and the excess of potentially exposed (borderline statistical significance) with urine WBC levels above the reference range. Both abnormalities were evaluated for their possible clinical significance. Raised urine protein and urine WBC might be considered of medical importance when found in conjunction with other abnormal laboratory or clinical findings; however, within the context of this study, they were judged not to be part of an overall clinical picture likely to be of biological importance relative to potential exposures to EO. Further clinical evaluation of the individuals with raised values showed that one of the potentially exposed had sperm in his urine while two others had lower urinary tract infections; longitudinal follow up of this group led to the conclusion that the raised concentrations were transitory in nature. In summary, the findings of our study are consistent with earlier work reported by Joyner, ${ }^{4}$ who found the frequency of abnormal laboratory findings to be the same in EO operators and matched controls. The only exception was the finding of an increased prevalence of proteinuria. Although considered insignificant on clinical grounds, it warrants further epidemiological monitoring on a longitudinal basis. The test is already incorporated into the routine medical surveillance of the employees.

We extend our sincerest thanks to the following for their contributions to this work: Ken Bodner and Ralph Cook, Dow Chemical USA, Jed Diem, Tulane University, Dirk VanPeenen, formerly of Dow Chemical USA and Mrs Alice Hammond and Angie Grzegorczyk, Dow Chemical USA.

\section{References}

' Anon. Chemical products synopsis ethylene oxide. Cortland, NY: Mannsville Chemical Products, 1979.

${ }^{2}$ Proctor NH, Hughes JP. Chemical hazards of the workplace. Philadelphia: JP Lippincott Co, 1978.

${ }^{3}$ Hine CH, Rowe VK. Epoxy compounds. In: Patty FA, ed. Industrial hygiene and toxicology, Vol II. 2nd ed. New York: John Wiley and Sons, 1963:1593-1654.

4 Joyner RE. Chronic toxicity of ethylene oxide. Arch Environ Health 1964;8:700-10.

s Garry VF, Hozier J, Jacobs D, Wade RL, Gray DG. Ethylene oxide: evidence of human chromosomal effects. Environ Mutagen 1979; 1:375-82.

- Gross JA, Haas ML, Swift TR. Ethylene oxide neurotoxicity: report of four cases and review of the literature. Neurology 1979;29:978-83.

' Snellings WM, Weil CS, Maronpot RR. Final report ethylene oxide two-year inhalation study on rats. Pittsburgh: Bushy Run Research Center Report, 1981:4-20.

8 Ehrenberg L, Hiesche KD, Osterman-Golkar S, Wennberg I. Evaluation of genetic risks of alkylating agents: tissue doses in the mouse from air contaminated with ethylene oxide. Mutat Res 1974; 24:83-103.

- Watson WAF. An essential difference between the genetical effects of mono- and bi-functional agents. Mutat Res 1966;3:455-7.

${ }^{10}$ Ehrenberg L, Gustafsson A. On the mutagenic action of ethylene oxide and diepoxybutane in barley. Hereditas 1957;43:595602.

"Embree JW, Hine CH. Mutagenicity of ethylene oxide. Toxicol Appl Pharmacol 1975;33:172-3.

12 Hogstedt C, Malmqvist M, Wadman B. Leukemia in workers exposed to ethylene oxide. JOM 1975;241:1132-3.

${ }^{13}$ Hogstedt C, Rohlen O, Berndtsson BS, Axelson O, Ehrenberg L. A cohort study of mortality and cancer incidence in ethylene 
oxide production workers. Br J Ind Med 1979;36:276-80.

${ }^{14}$ Morgan RW, Claxton KW, Divine BJ, Kaplan SD, Harris VB. Mortality among ethylene oxide workers. JOM 1981;23:767-70.

is Remington RD, Schork MA. Statistics with applications to the biological and health sciences. New Jersey: Prentice-Hall, Inc,
1970.

${ }^{16}$ Fleiss JL. Statistical methods for rates and proportions. New York: John Wiley \& Sons, 1973.

17 Conn HG, Conn RB Jr, eds. Current diagnosis 3. Philadelphia: WB Saunders Co, 1971. 